\title{
Lúpus eritematoso sistêmico bolhoso associado à doença de Kikuchi-Fujimoto: relato de caso como um desafio diagnóstico
}

\section{Bullous systemic lupus erythematosus associated with Kikuchi- Fujimoto disease: a case report as a diagnostic challenge}

Jéssica Gomes Carneiro ${ }^{1}$. Carlos Henrique de Oliveira Araújo ${ }^{1}$. Aline Salmito Frota ${ }^{1}$. Hercília Maria Carvalho Queiroz ${ }^{1}$. Juliana Maria Cavalcante Ribeiro Ramos ${ }^{2}$. José Telmo Valença Junior ${ }^{3}$. José Wilson Accioly Filho ${ }^{4}$.

1 Dermatologista ex-residente do Hospital Universitário Walter Cantídio (HUWC) - Universidade Federal do Ceará (UFC), Fortaleza - CE, Brasil. 2 Residente de dermatologia do Hospital Universitário Walter Cantídio (HUWC) - Universidade Federal do Ceará (UFC), Fortaleza - CE, Brasil. 3 Patologista, professor e preceptor da residência de Patologia do Hospital Universitário Walter Cantídio (HUWC) da Universidade Federal do Ceará (UFC), Fortaleza - CE, Brasil. 4 Dermatologista, professor, preceptor da residência e chefe do serviço de Dermatologia do Hospital Universitário Walter Cantídio (HUWC) da Universidade Federal do Ceará (UFC), Fortaleza - CE, Brasil.

\section{RESUMO}

O lúpus bolhoso é uma dermatose sistêmica rara, decorrente da presença de anticorpos contra o colágeno tipo VII da junção dermo-epidérmica. A doença de Kikuchi-Fujimoto pode se associar, embora raramente, ao lúpus e caracteriza-se por uma linfangite histiocitária necrotizante. Paciente masculino, 22 anos, com lesões vésico-bolhosas orais, no abdome, nádegas e axilas, além de adenomegalias dolorosas, bicitopenia, proteinúria, FAN fortemente positivo e serosites. $\mathrm{O}$ anatomopatológico sugeriu dermatite herpetiforme, mas a imunofluorescência direta revelou depósito linear de $\operatorname{IgG}$ e $\operatorname{IgA}$ na zona de membrana basal. A biópsia de linfonodo mostrou infiltrado linfohistiocitário CD8+ e CD68+ com necrose coagulativa. Os achados permitiram o diagnóstico de lúpus bolhoso associado à doença de Kikuchi-Fujimoto e o paciente respondeu satisfatoriamente ao tratamento empregado.

Palavras-chave: Lúpus. Buloses. Colágeno VII. Doença de Kikuchi-Fujimoto.

\section{ABSTRACT}

Bullous lupus is a rare systemic dermatosis, which is caused by antibodies against type VII collagen of the dermoepidermal junction. Although rarely, Kikuchi-Fujimoto disease can be associated with lupus and it is a histiocytic necrotizing lymphadenitis. Man, 22 years, presenting vesicolobullous lesions on the oral and genital mucosa, abdomen, buttocks, armpits and painful lymphadenomegaly, bicytopenia, proteinuria, ANF considerably positive and serositis. Skin histopathology was compatible with dermatitis herpetiformis, but direct immunofluorescence showed an IgG and IgA linear pattern on the basal membrane zone. Lymph node biopsy showed a CD8+ and CD68+ linfohistiocytic infiltrate surrounding a coagulative necrosis zone. Those clinical findings allowed the diagnosis of bullous lupus with Kikuchi-Fujimoto disease and the patient had a satisfactory response to the therapy.

Keywords: Lupus. Bullous dermatoses. Type VII collagen. Kikuchi-Fujimoto disease.

Autor Correspondente: Jéssica Gomes Carneiro. Rua Eusébio de Souza, 1645, apto 1702, Bairro Fátima, Fortaleza, Ceará. CEP: $60411-160$. Telefone: +55 (85) 32476228 / 99289896. E-mail: jessicagc1987@hotmail.com.

Conflito de interesses: Não há qualquer conflito de interesses por parte de qualquer um dos autores.

Recebido em: 13 Mar 2015; Revisado em: 14 Mai 2015; Aceito em: 14 Mai 2015. 


\section{INTRODUÇÃO}

O lúpus bolhoso (LESB) representa um subtipo raro de lúpus eritematoso sistêmico (LES) associado à presença de anticorpos contra o colágeno tipo VII das fibrilas de ancoragem na junção dermo-epidérmica. ${ }^{1}$ Acomete, em geral, mulheres jovens e caracteriza-se por erupção cutânea vésico-bolhosa, com ou sem prurido, presente também em áreas não fotoexpostas. No histopatológico, há bolha subepidérmica com microabscessos nas papilas dérmicas, fazendo diagnóstico diferencial, principalmente, com dermatite herpetiforme (DH). ${ }^{2} \mathrm{Na}$ imunofluorescência direta, ocorre depósito linear ou granular de IgG, IgM e IgA na zona de membrana basal. ${ }^{1,2}$

A doença de Kikuchi-Fujimoto também é infrequente e caracteriza-se por linfadenopatia dolorosa ou não, principalmente na região cervical e raramente generalizada. ${ }^{3}$ Afeta, preferencialmente, mulheres dos 20 aos 30 anos de idade e pode cursar com sintomas sistêmicos em até $50 \%$ dos casos. ${ }^{4}$ Pode-se associar a doenças infecciosas e auto-imunes. O histopatológico revela infiltrado linfo-histiocitário margeando uma zona de necrose, o que pode ser encontrado também na linfadenopatia do LES, diferenciando-se desta pela ausência de neutrófilos.

\section{RELATO DO CASO}

Paciente masculino, 22 anos, com diagnóstico prévio de tireoidite de Hashimoto, sem controle satisfatório com $100 \mathrm{mcg}$ de levotiroxina $(\mathrm{TSH}>98 \mathrm{mUI} / \mathrm{ml}$ ), compareceu a consulta médica com febre, adinamia e surgimento, na última semana, de vésico-bolhas dolorosas nos lábios e cavidade oral (Figura 1), agrupadas em base eritematosa, com crostas melicéricas e sero-hemorrágicas.

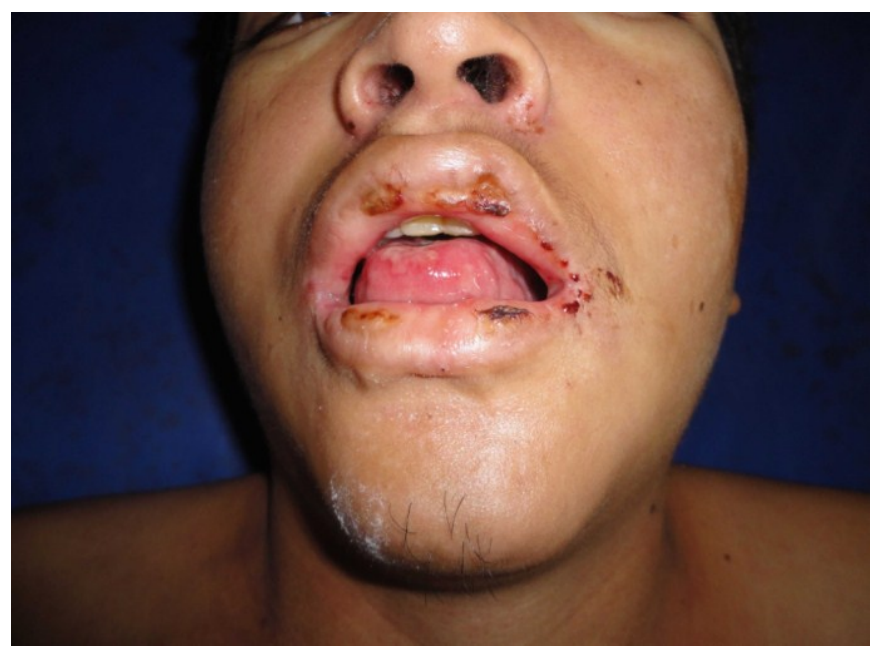

Figura 1. Lesões vésico-bolhosas dolorosas nos lábios e cavidade oral, agrupadas em base eritematosa, com crostas melicéricas e sero-hemorrágicas, com uma semana de evolução.

Foi iniciado tratamento com aciclovir e ampicilina + sulbactam endovenosos, mas no $5^{\circ}$ dia houve surgimento de lesões vésico-bolhosas novas no abdome e genitália (Figura 2), axilas e nádegas (Figuras 3), além de adenomegalias dolorosas cervicais, axilares e inguinais. Foi prescrito $50 \mathrm{mg} /$ dia de metilprednisolona endovenosa, sem melhora significativa após sete dias.

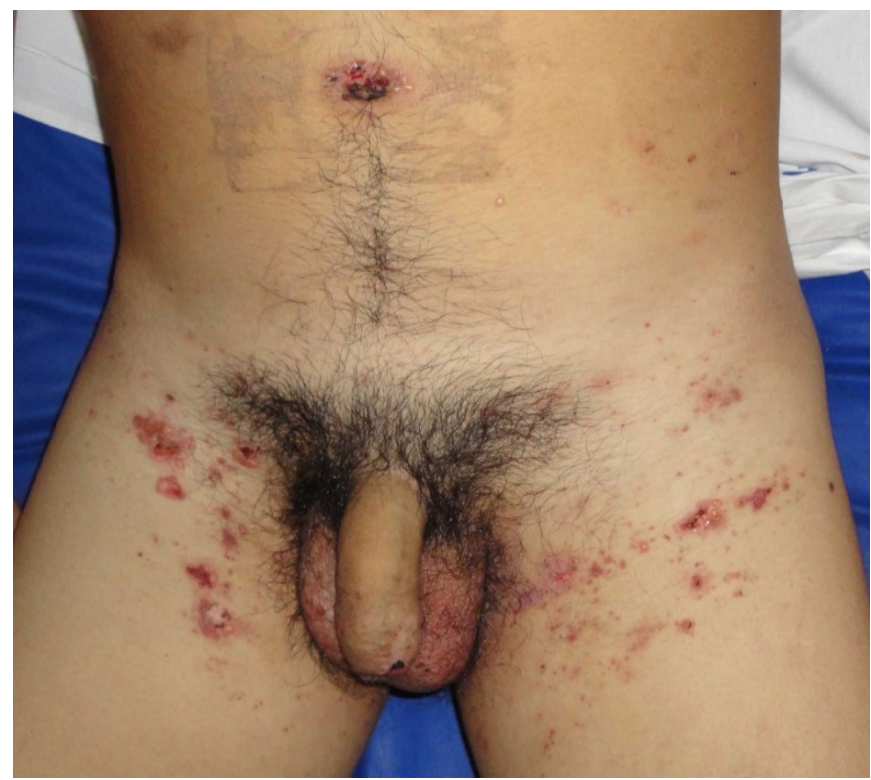

Figura 2. Lesões vésico-bolhosas que surgiram no quinto dia de internação hospitalar, no abdome e genitália.
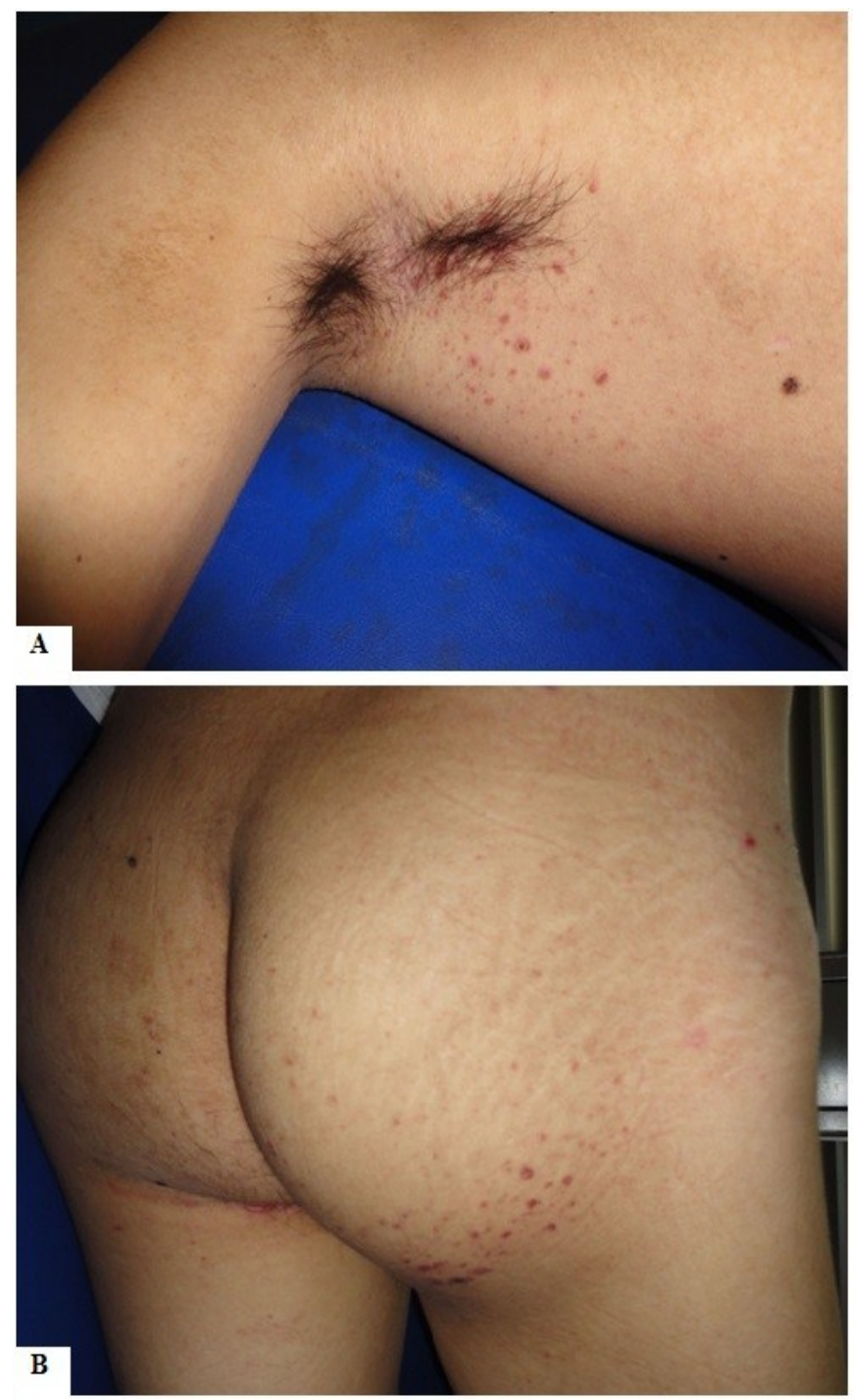

Figura 3. Demais lesões vésico-bolhosas que surgiram no quinto dia de internação hospitalar, na região axilar (A) e nas nádegas (B). 
Os exames laboratoriais mostraram anemia hemolítica $(\mathrm{Hb}$ : 8,23g/dl e Coombs direto positivo), linfopenia (402 células), VHS: $50 \mathrm{~mm} / \mathrm{h}$, PCR: $6,6 \mathrm{mg} / \mathrm{l}, \mathrm{C} 3: 12 \mathrm{mg} / \mathrm{dl}$ (valor de referência: $87-200 \mathrm{mg} / \mathrm{dl}$ ) e C4: $2 \mathrm{mg} / \mathrm{dl}$ (valor de referência: 10-52mg/dl), Creatinina sérica: 1,4mg/dl, FAN 1:1280 pontilhado grosso e sorologias virais negativas. O sumário de urina revelou $2+$ de proteínas e $1+$ de hemoglobina (presença de dismorfismo eritrocitário) e a proteinúria de 24 horas foi de $1476 \mathrm{mg} /$ dia. A ultrassonografia tóraco-abdominal mostrou ascite de pequeno volume, adenomegalias mesentéricas, derrame pleural discreto e pericárdico moderado.

A biópsia cutânea revelou bolha subepidérmica, microabscessos de neutrófilos nas papilas dérmicas e infiltrado inflamatório misto principalmente na derme superficial (Figura 4), sugestivo de DH. A pesquisa de intolerância ao glúten (antigliadina, antiendomísio e antitransglutaminase tecidual) foi negativa. $\mathrm{Na}$ imunofluorescência direta de pele perilesional houve depósito linear de IgG e IgA na zona de membrana basal.
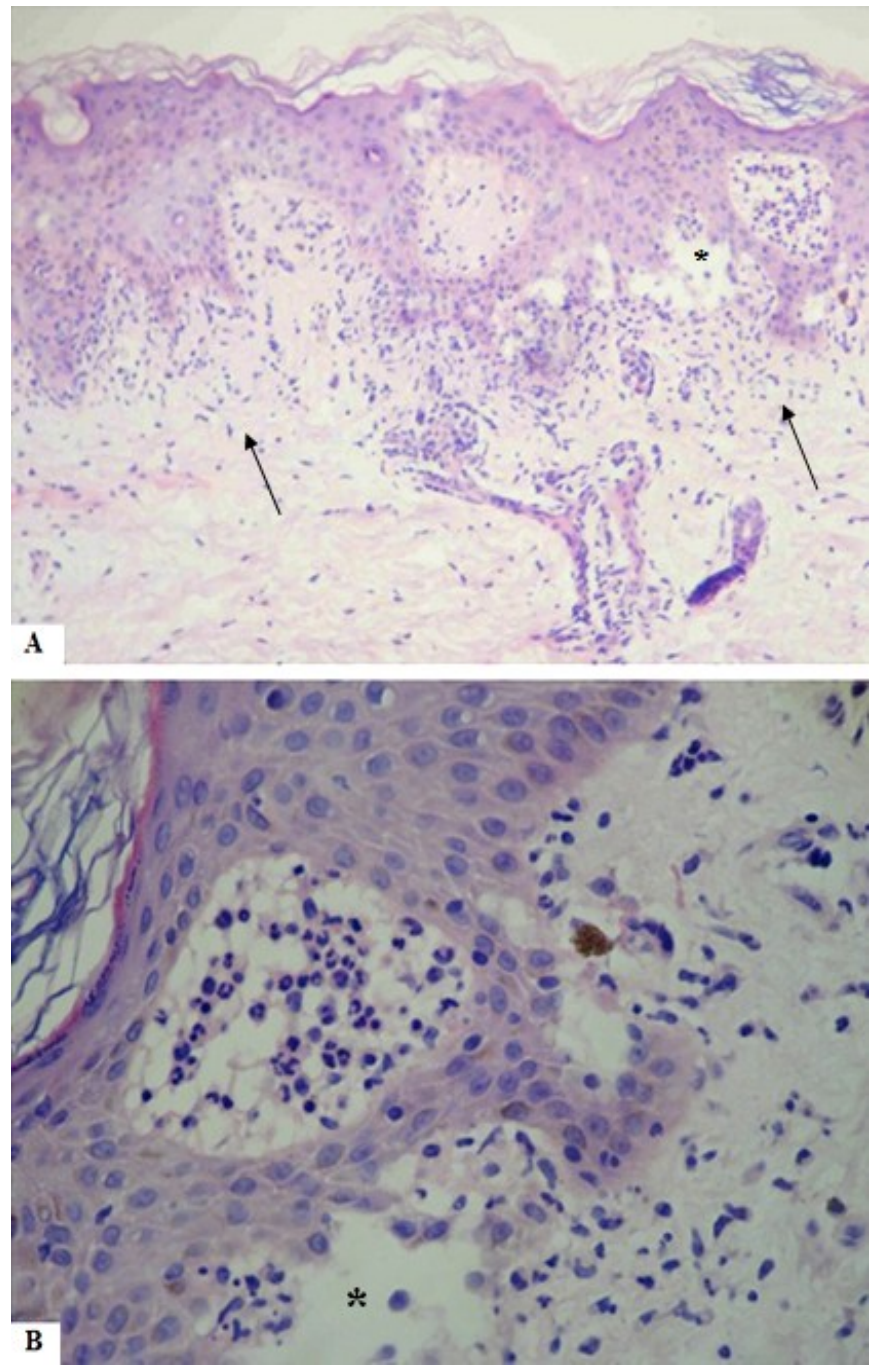

Figura 4. A. Biópsia de pele mostrando bolha subepidérmica $(*)$ com microabscessos de neutrófilos nas papilas dérmicas e infiltrado inflamatório misto (setas) principalmente na derme superficial (HE, 10x). B. Microabscesso de neutrófilos na papila dérmica, área de descolamento subepidérmico adjacente $(*)$ e derrame pigmentar (HE, 40x).
A biópsia de linfonodo inguinal mostrou necrose coagulativa central, sem neutrófilos de permeio, cerceada por infiltrado linfo-histiocitário (Figura 5), com imunohistoquímica positiva para CD8 e CD68.

Estabeleceu-se, portanto, tratamento com dapsona 100mg/dia e prednisona $60 \mathrm{mg} /$ dia, além de progressão da antibioticoterapia para vancomicina com polimixina B endovenosas, pelo agravamento da infecção bacteriana nas lesões. Foi realizado, também, drenagem pericárdica de $450 \mathrm{ml}$ de líquido citrino e estéril.

Houve melhora do quadro clínico após 2 meses de tratamento, inclusive dos parâmetros laboratoriais, dentre eles o VHS: $16 \mathrm{~mm} / \mathrm{h}, \mathrm{C} 3: 92 \mathrm{mg} / \mathrm{dl}, \mathrm{C} 4: 21 \mathrm{mg} / \mathrm{dl}$ e proteinúria de 24 horas de $187 \mathrm{mg} /$ dia. Iniciou-se desmame lento do corticoide e, em 12 meses de seguimento, o paciente manteve-se estável com $5 \mathrm{mg} /$ dia de prednisona e $50 \mathrm{mg} /$ dia de dapsona.
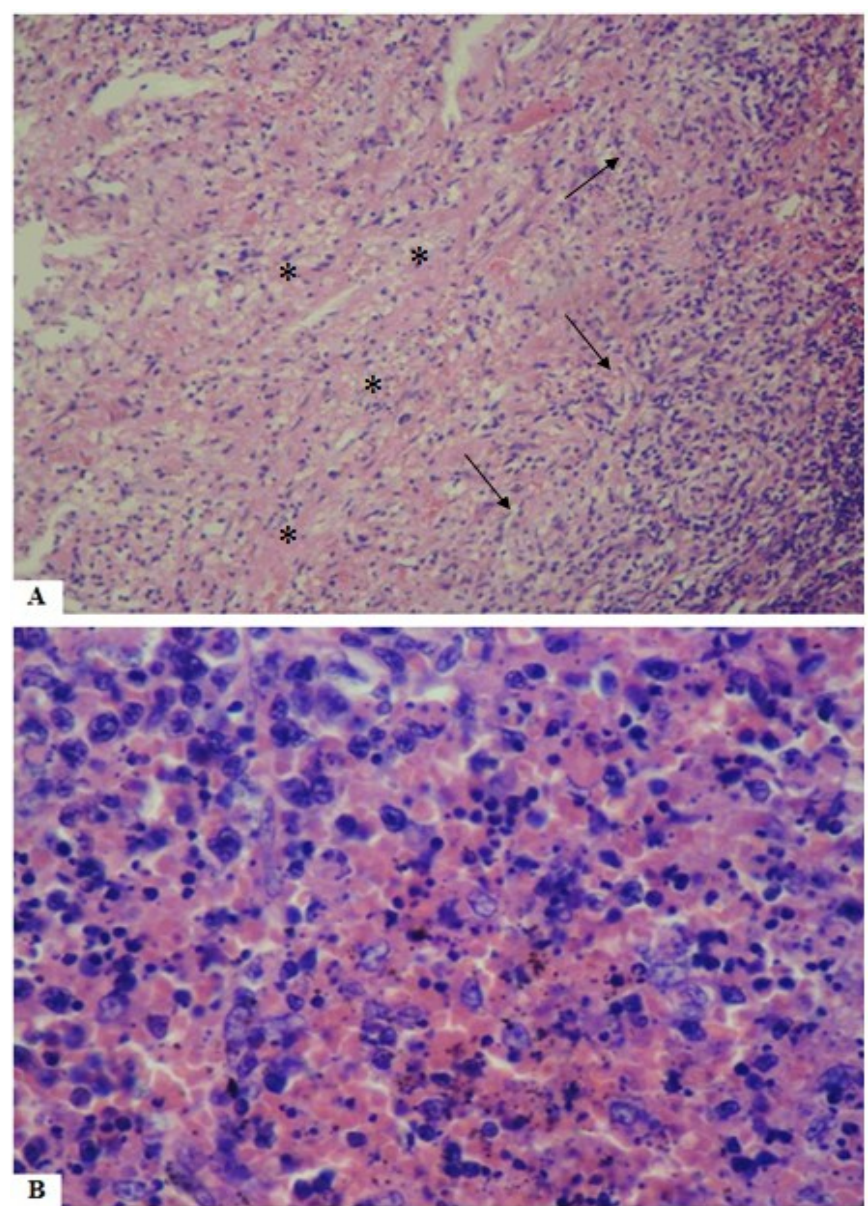

Figura 5. A. Biópsia de linfonodo revelando necrose coagulativa central $\left(^{*}\right)$, sem neutrófilos de permeio, cerceada por infiltrado linfo-histiocitário (setas) - HE, 10x. B. Detalhe do infiltrado inflamatório linfo-histiocitário entremeado por restos nucleares, com material necrótico eosinofílico no plano de fundo (HE, 40x).

\section{DISCUSSÃO}

O LES cursa com lesões cutâneas em 60 a 90\% dos pacientes, mas apenas 5\% são bolhosas, podendo coincidir ou não com a atividade sistêmica. ${ }^{5,6}$ Nesses casos, dois diagnósticos são suscitados: LES com bolhas e LESB. 
No LES com bolhas não há formação de anticorpos contra o colágeno tipo VII e as lesões são policíclicas e restritas às áreas fotoexpostas. $\mathrm{Na}$ histopatologia observa-se intensa degeneração hidrópica da camada basal e edema da derme superior, ${ }^{1}$ por deposição de imunocomplexos, radiação ultravioleta e/ou títulos elevados de Anti-Ro, o que gera a formação bolhosa.,

Já o LESB, que representa apenas 2 a 3\% das dermatoses bolhosas auto-imunes, ${ }^{7}$ demonstra: LES pelos critérios da Academia Americana de Reumatologia ${ }^{5}$ (Tabela 1); Vesículas e bolhas em áreas fotoexpostas ou não; Histologia compatível com DH; Imunofluorescência indireta negativa para anticorpos anti-membrana basal; Imunofluorescência direta com $\operatorname{IgG}, \operatorname{IgM}$ e $\operatorname{IgA}$ na camada basal, atingindo o colágeno tipo VII. ${ }^{8}$

Tabela 1. Critérios diagnósticos sumarizados de LES, baseados na atualização de 2012 da Academia Americana de Reumatologia (Systemic Lupus International Collaborating Clinics - SLICC). ${ }^{5}$

Requisitos: $\geq 4$ critérios (pelos menos 1 critério clínico e 1 laboratorial) ou biópsia renal com nefrite lúpica e anticorpos anti-nucleares ou Anti-DNA positivos

\section{Critérios clínicos}

Lúpus cutâneo agudo*ou subagudo

Lúpus cutâneo crônico

Úlceras orais ou nasais

Alopécia não cicatricial

Artrite/Artralgias/Sinovites

Serosites

Acometimento renal

Acometimento neurológico

Anemia hemolítica

Leucopenia

Trombocitopenia

$\left(<100000 / \mathrm{mm}^{3}\right)$

*Eritema malar; Eritema maculopapuloso difuso na face, couro cabeludo, pescoço, tórax, ombros, face extensora dos braços e dorso das mãos; Lúpus bolhoso.

${ }^{+}$Papuloescamoso (psoriasiforme); Anular (policíclico).

${ }^{\S}$ Discoide e suas variantes; Verrucoso; Túmido; Profundo; Mucoso; Pérnio.

Os achados mais precoces do LESB podem ser confundidos com herpes simples, pênfigo vulgar, doença de Behçet, epidermólise bolhosa adquirida e penfigóide bolhoso, como ocorrido com o paciente em questão. Devido ao agravamento clínico e sistêmico e aos achados nos exames complementares, LESB e seus principais diagnósticos diferenciais, DH e dermatose por IgA linear, foram enfocados. ${ }^{2,6}$

A DH frequentemente apresenta anticorpos marcadores de intolerância ao glúten e a imunofluorescência direta possui IgA granular nas papilas dérmicas. ${ }^{2}$ Já na dermatose por IgA, a deposição é linear e única. No LESB, pode ocorrer depósito de IgA em $65 \%$ dos casos, mas há IgG e/ou IgM também. ${ }^{6,7,8}$

O LESB não responde à corticoterapia isolada, sendo a dapsona a mais eficaz e com resposta rápida. ${ }^{6,8}$ Os casos refratários ou impossibilitados de usar dapsona podem ser controlados com colchicina ou corticoide associado a uma medicação adjuvante como os imunossupressores e antimaláricos. ${ }^{2}$

A doença de Kikuchi-Fujimoto é encontrada em até 5\% dos casos de adenomegalias analisadas histologicamente. ${ }^{9}$ Podese associar a etiologias infecciosas como herpesvírus, HTLV1, parvovírus B19, parainfluenza, Yersinia sp e toxoplasma. ${ }^{10}$ É descrito, também, associação com doenças auto-imunes, como o LES (principal) e a tireoidite de Hashimoto, ${ }^{3,4}$ conforme observado no paciente do presente relato.

Embora os sintomas sistêmicos estejam presentes em até metade dos casos, a multiplicidade de linfonodos acometidos chega até $5 \% .^{3,10} \mathrm{O}$ quadro clínico característico é de adenomegalia dolorosa ou não na região cervical de uma mulher jovem e com tendência a resolução espontânea, embora alguns pacientes se beneficiem de baixas doses de corticoide. $^{10}$

Pode cursar com bicitopenias em até $70 \%$ dos casos e aumento de VHS, LDH e transaminases. Anticorpos antinucleares e anticoagulante lúpico podem ser positivos. ${ }^{3,4,10}$

Os achados histológicos podem ser divididos em 3 fases de mecanismo desconhecido: ${ }^{10}$ 1) Lesão linfoproliferativa com abundantes células mononucleares atípicas; 2) Linfangite necrotizante com histiócitos destruindo a arquitetura linfonodal, sem infiltrado neutrofílico, achado este encontrado no paciente exposto; 3) Reabsorção da necrose e recuperação arquitetural.

Os principais diagnósticos diferenciais são: neoplasias linfoproliferativas e metastáticas, infecções sistêmicas (ex: HIV), vasculites e sarcoidose. ${ }^{9,10}$ A confirmação definitiva se faz pelo histopatológico com imunohistoquímica, com positividade principalmente para CD8, CD11, CD14 e CD68. ${ }^{3,10}$

Embora sejam doenças raras, principalmente em homens jovens, o paciente deste relato reúne achados compatíveis com LESB e doença de Kikuchi-Fujimoto, demonstrando a importância e, ao mesmo tempo, a complexidade da abordagem de um quadro clínico como este. 


\section{REFERÊNCIAS}

1. Obermoser G, Sontheimer RD, Zelge B. Overview of common, rare and atypical manifestations of cutaneous lupus erythematosus and histopathological correlates. Lupus. 2010;19(9):1050-70.

2. Barbosa WS, Rodarte CM, Guerra JG, Maciel VG, Fleury LF Jr, Costa MB. Lúpus eritematoso sistêmico bolhoso - diagnóstico diferencial com dermatite herpetiforme. An Bras Dermatol. 2011;86(4 Supl 1):S92-5.

3. Bogusz AM, Bhargava P. Recurrent histiocytic necrotizing lymphadenitis with a long latency in a patient with autoimmunity: a case report and review of literature. Int J Surg Pathol. 2013;21(3):287-96.

4. Ruaro B, Sulli A, Alessandri E, Fraternali-Orcioni G, Cutolo M. Kikuchi-Fujimoto's disease associated with systemic lupus erythematous: difficult case report and literature review. Lupus. 2014;23(9):939-44

5. Petri M, Orbai AM, Alarcón GS, Gordon C, Merrill JT, Fortin $\mathrm{PR}$, et al. Derivation and Validation of the Systemic Lupus International Collaborating Clinics classification criteria for systemic lupus erythematosus. Arthritis Rheum. 2012;64(8):267786.
6. Tincopa M, Puttgen KB, Sule S, Cohen BA, Gerstenblith MR. Bullous lupus: an unusual initial presentation of systemic lupus erythematosus in an adolescent girl. Pediatr Dermatol. 2010;27(4):373-6.

7. Hooten J, Hall R 3rd, Cardones A. Updates on the management of autoimmune blistering diseases. Skin Therapy Lett. 2014;19(5):1-6.

8. Contestable JJ, Edhegard KD, Meyerle JH. Bullous systemic lupus erythematosus: a review and update to diagnosis and treatment. Am J Clin Dermatol. 2014;15(6):517-24.

9. Mohan A, Reddy MK, Phaneendra BV, Chandra A. Aetiology of peripheral lymphadenopathy in adults: analysis of 1724 cases seen at a tertiary care teaching hospital in southern India. Natl Med J India. 2007;20(2):78-80.

10. Jamal AB. Kikuchi Fujimoto disease. Clin Med Insights Arthritis Musculoskelet Disord. 2012;5:63-6.

\section{Como citar:}

Carneiro JG, Araújo CH, Frota AS, Queiroz HM, Ramos JM, Valença JT Jr, et al. Lúpus erimatoso sistêmico bolhoso associado à doença de kikuchi-fujimoto: relato de caso como um desafio diagnóstico. Rev Med UFC. 2015 jan-jun;55(1):47-51. 